Z. klin. Chem. u. klin. Biochem.

8. Jg., S. $27-29,1970$

\title{
Eine Störung durch Elektrolyte bei der Färbung elektrophoretisch aufgetrennter Eiweißkörper mit Amidoschwarz 10B
}

\author{
Von H. Wachter, W. Gütter, A. Hausen und G. Sallaberger \\ Aus dem Institut für Mediqiniscbe Chemie der Universität Innsbruck (Vorstand: Prof. Dr. R. Stöbr)
}

(Eingegangen am 9. August 1969)

Elektrolyte in minimalen Konzentrationen, wie sie in Methylalkohol purissimum enthalten scin können, verursachen bei der Entfärbung von mit Amidoschwarz 10B angefärbten Serumelektrophoresestreifen durch Herauslösen von Farbstoff eine scheinbare Verschiebung der Relativprozente der Proteinfraktionen. Solche falschen Ergebnisse können durch ein einfaches Prüfverfahren vermieden werden. Es wird der Einfluß unterschiedlicher Elektrolyte auf die Entfärbung der einzelnen papierelektrophoretisch aufgetrennten Eiweißbanden untersucht und mit Radiokobalt eine Verdrängung des Amidoschwarz 10B vom Eiweiß durch Elektrolytc gefunden.

\section{Interference by electrolytes in the location of proteins with Amidoschwarz $10 B$ on electrophoretograms}

Minimal concentrations of electrolytes, such as may be present in methyl alcohol purissimum, cause an apparent shift in the relative percentages of the protein fractions measured on serum electrophoresis strips with Amidoschwarz 10B; somc dyc is leached from the protein during the destaining procedure. These false results can be avoided by a simple test procedure. The leaching of the Amidoschwarz 10B from protein by various electrolytes is determined with radio-cobalt during the destaining of single protein bands separated on paper electrophoretograms.

Die Färbung elektrophoretisch aufgetrennter Proteine mit Amidoschwarz 10B nach Grassmann und HanNig (1) erfolgt in zwei Teilschritten. Zuerst wird der gesamte Streifen gleichmäßig angefärbt; farbfreie Bäder dienen beim zweiten Schritt zum möglichst vollständigen Entfernen des nicht an Eiweiß gebundenen Farbstoffes.

Im Verlaufe der letzten Jahre beobachteten wir bei der Durchführung dieses Färbeprozesses im Routinelaboratorium wiederholt Störungen, die nicht durch den Farbstoff bedingt waren. Aus den Eiweißbanden wurden unterschiedliche Farbstoffmengen herausgelöst, wodurch die quantitativen Ergebnisse der Elektrophorese verfälscht wurden. Untersuchungen der verwendeten Reagenzien zeigten, daß die Störungen durch Methylalkohol verursacht wurden. Es handelte sich um vereinzelte Chargen von Methylalkohol purissimum, den wir aus wirtschaftlịchen Gründen im Routinebetrieb verwenden.

Ziel dieser Arbeit war, die Ursache dieser Störung aufzufinden. Ein einfaches Prüfverfahren der Lösungsmittelchargen auf Tauglichkeit zur Verwendung für die Entfärbung sollte angegeben werden. Auch schien es interessant, ob Aussagen übẹr den Mechanismus der Störreaktion gemacht werden können.

\section{Material und Methodik}

\section{Geräte}

Eiweißfärbung: Elektropheromat, Fa. Seibold, Wien (2).

Photometrie: Quarzspektrophotometer, Modell DU, Beckman, South Pasadena, Calif.

Elektrophorese und Transparenzphotometrie: Elphor, Fa. Bender und Hobein, München.

Scbilttelgerät: Elphor-Wippe, Fa. Bender und Hobein, München. Röntgenfluoreszenzanalyse: Kristalloflex $4 \mathrm{mit}$ Vakuumzusatz, Fa. Siemens, Karlsruhe.
Messung der Radioaktivität: Geiger-Müller-Zählstand FH 49, Fa. Frieseke und Hoepfner, Erlangen/Bruck.

\section{Reagenzien}

Amidoschwarz 10B, Merck; Eisessig p. a., Merck; Methanol p. a., Merck; Methylalkohol purissimum, Heilmittelwerke, Wien.

Methoden

Elektrophorese nach GrassmanN und HANNIG (1), Trocknung der Streifen mit Ventilator, Eiweißfärbung (2) mit Amidoschwarz 10B in Mcthylalkohol/Eisessig 9:1 ( $\mathrm{v} / \mathrm{v})$, Entfärbelösung Methylalkohol/Eisessig 9:1 ( $/ / \mathrm{v})$.

\section{Experimentelles}

Eine Charge Methylalkohol purissimum, die die bereits erwähnte Störung zeigte, wurde fraktioniert destilliert. Die störenden Bestandteile befanden sich im Destillationsrückstand. Die Röntgenfluoreszenzanalyse des Rückstandes ergab als Hauptbestandteil Zinksulfat in etwa $0,002 \mathrm{Gew} \%$ bezogen auf Methylalkohol. Daneben waren noch Spuren freier Schwefelsäure und Wasser enthalten.

Zur Uberprüfung der Lösungsmittel auf ihre Verwendbarkeit zur Entfärbung fanden wir folgendes einfaches Verfahren (Abb. 1): Ein mit Amidoschwarz 10B unter Verwendung von p. a. Lösungsmitteln gefärbter und entfärbter Elektrophoresestreifen wird mit $100 \mathrm{~m} /$ Entfärbelösung, dic das zu prüfende Lösungsmittel als Bestandteil enthält, auf der Wippe $10 \mathrm{Min}$. geschüttelt.

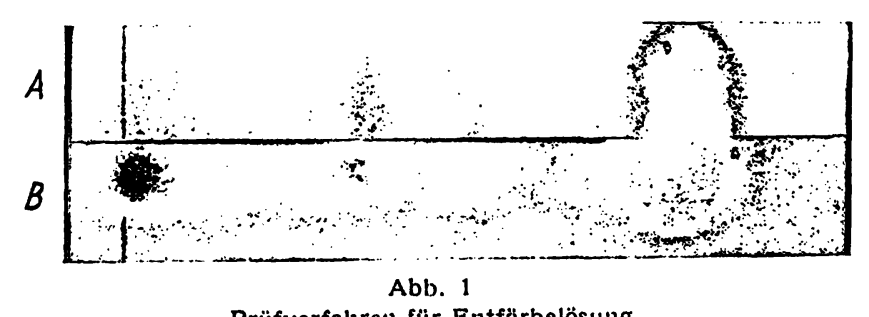

Prüfverfalıren für Entfärbelösung

Ein mit p.a. Reagenzien gefärbter und entfärbter Elektrophoresestreifen wird der Lănge nach durchsclinitten. Eine Hälfte des Streifens (B) dient als Vergleichsstreifen, die andere Hälfte (A) wird $10 \mathrm{Min}$. in $100 \mathrm{ml}$ der zu prüfenden Entfärbelösung gewippt. Der Streifen A wurde in diesem Falle deutlich entfärbt. Das Methanol war mit $0,002 \mathrm{Gew} \%$ Zinksulfat verunreinigt. Lüge keine Verunreinigung vor so wärde der Streifen A auch nach dieser Behandlung dem Streifen $B$ in seiner Farbintensität vollkommen gleichen 
Nicht einwandfreic Reagenzien bewirken durch weiteres Herauslösen von Farbstoff aus den Eiweißbanden eine Blaufärbung der Entfärbelösung, die durch Photometrie $(595 \mathrm{~nm})$ quantitativ verfolgt werden kann. Einwandfreie Reagenzien bleiben völlig farblos. Ein derart überprüftes Lösungsmittel entspricht in seiner Tauglichkeit zur Verwendung in Entfärbebädern einem p. a. Präparat.

Mit dieser Methode wurde der Einfluß unterschiedlicher Elektrolyte auf den Entfärbevorgang quantitativ untersucht. Mit dem gleichen Serum beladene Streifen wurden nach elektrophoretischer Auftrennung mit Amidoschwarz 10B in Methylalkohol p. a./ Eisessig p. a. 9:1 (v/v) gefärbt und entfärbt. Die gefärbten Streifen schüttelten wir $10 \mathrm{Min}$. in einem Bad mit $50 \mathrm{~m} l$ Entfärbelösung (p. a. Präparate) unter Zusatz von $6,2 \mu \mathrm{Mol}$ unterschiedlicher Elektrolyte. Photometrieren der schwach blau gefärbten Lösung ergab die von den eingesetzten Elektrolyten herausgelösten Mengen Amidoschwarz 10B (Tab. 1).

Tab. 1

Menge von Amidoschwarz 10B, die durch Zusatz von 6,2 $\mu$ Mol Elektrolyt zu $50 \mathrm{ml}$ Entfärbelösung aus gefärbten Elektrophoresestreifen herausgelöst wurde

\begin{tabular}{ll}
\hline Elektrolyt & $\begin{array}{c}\text { Amidoschwarz 10B } \\
\text { in mg }\end{array}$ \\
\hline $\mathrm{NH}_{4} \mathrm{Cl}$ & 0,018 \\
$\mathrm{NH}_{4} \mathrm{NO}_{3}$ & 0,017 \\
$\mathrm{NH}_{4} \mathrm{~J}$ & 0,016 \\
$\mathrm{ZnCl}_{2}$ & 0,018 \\
$\left.\mathrm{Zn}_{2} \mathrm{NO}_{3}\right)_{2}$ & 0,017 \\
$\mathrm{Na}_{3} \mathrm{PO}_{4}$ & 0,005 \\
$\mathrm{NaBr}$ & 0,004 \\
$\mathrm{NaNO}_{3}$ & 0,003 \\
$\mathrm{NaF}$ & 0,003 \\
$\mathrm{NaCl}$ & 0,001 \\
$\mathrm{H}_{2} \mathrm{SO}_{4}$ & 0,043 \\
$\left(\mathrm{NH}_{4}\right)_{2} \mathrm{SO}_{4}$ & 0,039 \\
$\mathrm{Na}_{2} \mathrm{SO}_{4}$ & 0,033 \\
$\mathrm{CoSO}_{4}$ & 0,031 \\
$\mathrm{MgSO}_{4}$ & 0,029 \\
$\mathrm{ZnSO}_{4}$ & 0,029 \\
$\mathrm{~K}_{2} \mathrm{SO}_{4}$ & 0,026 \\
$\mathrm{CdSO}_{4}$ & 0,024 \\
$\mathrm{FeSO}_{4}$ & 0,020 \\
$\mathrm{CuSO}_{4}$ & 0,018 \\
$\mathrm{CaSO}_{4}$ & 0,007 \\
$\mathrm{MnSO}_{4}$ & 0,006 \\
\hline
\end{tabular}

Zur Untersuchung, ob bei dem Entfärbevorgang Ionen an Protein gebunden werden, erschienen in Anbetracht der geringen Substanzmengen nur radiochemische Methoden erfolgversprechend. Ein mit Serumprotein beladener, gefärbter Elektrophoresestreifen

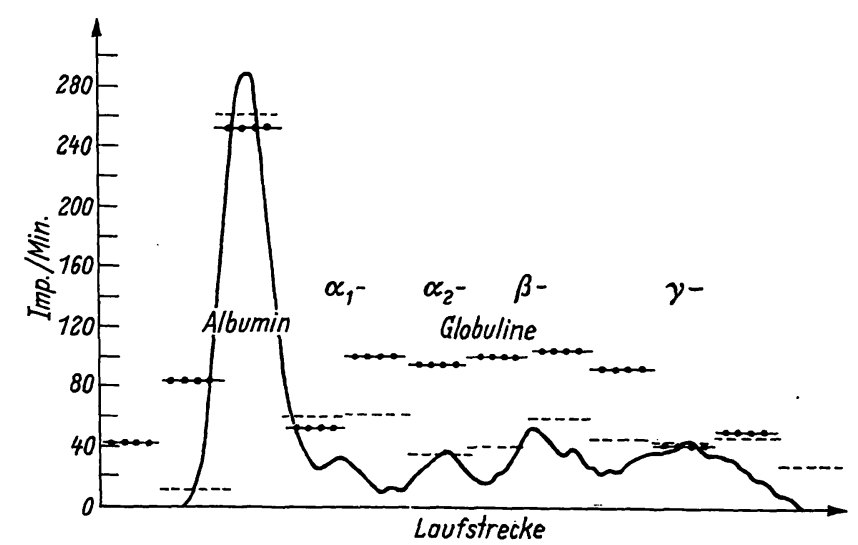

Abb. 2

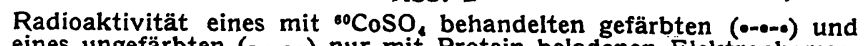
eines ungefärbten (---) nur mit Protein beladenen Elektrophoresestreifens und Elektropherogramm ( $\longrightarrow)$ derselben Streifen. Das

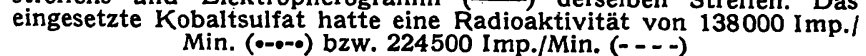

Tab. 2

Einwirkung der Färbelösung (a) bzw. der Entfärbelösung (b) auf die Einwirkung der Farbelosung (a) bzw. ${ }^{\circ} \mathrm{CoSO}$ beladenen ElektroRadioaktivität eines angefärbten mit
phoresestreifens

\begin{tabular}{llrc}
\hline & Ausgangswert & Einwirkung $10 \mathrm{Min}$. & Einwirkung $30 \mathrm{Min}$. \\
\hline a) & $730 \mathrm{Imp} . / \mathrm{Min}$. & $95 \mathrm{Imp} . / \mathrm{Min}$. & $5 \mathrm{Imp} . / \mathrm{Min}$. \\
b) & $704 \mathrm{Imp} / \mathrm{Min}$. & $187 \mathrm{Imp} / \mathrm{Min}$. & $50 \mathrm{Imp} / \mathrm{Min}$. \\
\hline
\end{tabular}

Tab. $3 \cdot 1$

Einwirkung von Elektrolytzusatz auf die quantitative Auswertung (rel.-\%) von Serumeiweißelektrophoresen

\begin{tabular}{|c|c|c|c|c|c|}
\hline Elektrolyt & Albumin & $\alpha_{1-}$ & $\alpha_{2-}$ & $\begin{array}{c}\beta= \\
\text { Globulin }\end{array}$ & $\gamma-$ \\
\hline $\begin{array}{l}\text { ohne Zusatz } \\
\mathrm{Na}_{2} \mathrm{SO}_{4} \\
\mathrm{ZnSO}_{4} \\
\mathrm{CoSO}_{4} \\
\left(\mathrm{NH}_{4}\right)_{2} \mathrm{SO}_{4}\end{array}$ & $\begin{array}{l}56,6 \\
59,8 \\
62,8 \\
65,7 \\
62,9\end{array}$ & $\begin{array}{l}5,2 \\
4,7 \\
5,0 \\
3,4 \\
4,6\end{array}$ & $\begin{array}{l}7,6 \\
6,9 \\
6,5 \\
4,8 \\
8,0\end{array}$ & $\begin{array}{l}14,1 \\
13,4 \\
10,9 \\
10,9 \\
10,4\end{array}$ & $\begin{array}{l}16,5 \\
15,2 \\
14,8 \\
15,2 \\
14,1\end{array}$ \\
\hline
\end{tabular}

wurde mit jeweils $50 \mathrm{ml}$ Methylalkohol p. a./Eisessig p. a. (9:1) $(v / v)$ unter Zusatz von trägerfreiem ${ }^{60} \mathrm{CoSO}_{4} 10 \mathrm{Min}$. geschüttelt. Der Streifen wurde nach dem Trocknen in $1 \mathrm{~cm}$ breite Stücke zerschnitten und deren Rädioaktivität mit dem Geigerzäbler gemessen. In der gleichen Weise behandelten wit auch einen mit Serumprotein beladenen, nicht gefärbten Streifen. Mittelwerte aus 3-5 Messungen sind in der Abbildung 2 zusammen mit der transparenzphotometrischen Auswertung des gefärbten Streifens gezeigt. Die beiden Versuche ergaben eine deutliche Steigerung der Radioaktivität an den Positionen der Proteinfraktionen.

Geringe Elektrolytmengen im Farbbad stören die Anfärbung nicht. Serumelektrophoresestreifen, die durch Entfärbelösungen mit Elektrolytzusatz entfärbt wurden, ergeben nach neuerlicher Anfärbung mit elektrolytfreien Lösungsmitteln bei quantitativer Auswertung korrekte Ergebnisse (3). Diese Beobachtungen können befriedigend durch die Annahme einer gegenseitigen Verdrängung von Farbstoff und Elektrolyt erklärt werden. Den Nachweis dieser Annahme erbrachten Experimente mit bereits angefärbten und mit ${ }^{60} \mathrm{Co}^{++}$beladeñen Streifen. Nochmaliges Einfärben der Streifen führte zu einem vollständigen Verlust der Radioaktivität, auch an den Stellen der Proteinbanden. Im Gegensatz dazu zeigten gleich angefärbte, mit ${ }^{60} \mathrm{Co}^{++}$markierte Serumelektrophoresestreifen nach Digerieren mit den gleichen Lösungsmitteln ohne Farbzusatz einen deutlichen Erhalt der Aktivität (Tab. 2).

In einer weiteren experimentellen Reihe sollte untersucht werden, ob der prozentuale Farbverlust bei Elektrolytzusatz für die einzelnen Proteinfraktionen variiert und ob für unterschiedliche Kationen Differenzen bestehen. Mit Amidoschwarz 10B ${ }^{\wedge}$ gefärbte Elektrophoresestreifen des gleichen Serums wurden mit $50 \mathrm{ml}$ Methylalkohol p. a./Eisessig p. a. $(9: 1)$ (v/v) unter Zusatz von jeweils 6,2 $\mu \mathrm{MolNa} \mathrm{Na}_{4}, \mathrm{ZnSO}_{4}, \mathrm{CoSO}_{4}$ und $\left(\mathrm{NH}_{4}\right)_{2} \mathrm{SO}_{4} 10 \mathrm{Min}$. geschüttelt. Die Relativprozente der transparenzphotometrischen Auswertung dieser Streifen (Mittelwerte von jeweils 2 Bestimmungen) sind in Tabelle 3 angeführt.

\section{Ergebnisse und Diskussion}

Eine Störung der Eiweißfärbung mit Amidoschwarz 10B wurde auf den zweiten Teilschritt, die Entfärbung in farbstofffreien Bädern, lokalisiert. Die Ursache bestand in einer Verunreinigung des Methylalkohols mit Spuren von Zinksulfat. Wir haben ein einfaches Verfahren angegeben, mit dem jede Charge des Lösungsmittels geprüft werden kann, ob sie zur Entfärbung tauglich ist; mit dieser Methode wurde die Störung bei Zusatz von Elektrolyten quantitativ untersucht. Aus Tabelle 1 ist ersichtlich, daß alle in höherem Maße wirksamen Verbindungen Sulfate sind. Der Effekt ist jedoch nicht nur aufgrund der Wirkung des Sulfats zu erklären. Vergleicht 
man die Sulfate folgender Kationen, erhält man die Reihung $\mathrm{H}^{+}>\mathrm{NH}_{4}^{+}>\mathrm{Na}^{+}>\mathrm{Co}^{++}>\mathrm{Mg}^{++}=\mathrm{Zn}^{++}$ $>\mathrm{K}^{+}>\mathrm{Cd}^{++}>\mathrm{Fe}^{++}>\mathrm{Cu}^{++}>\mathrm{Ca}^{++}>\mathrm{Mn}^{++}$, die weitgehend parallel mit der Bindungsfähigkeit der Serumproteine für diese Kationen verläuft $(5,6)$.

Unsere Experimente mit radioaktiv markiertem Kobalt haben gezeigt, daß die Radioaktivität an den einzelnen Eiweißfraktionen Maxima aufweist; durch Nachfärben mit Amidoschwarz 10B geht die Radioaktivität wieder verloren. Daraus schließen wir, daß Farbstoff und Elektrolyte einander verdrängen.

Aufgrund der für ein Ion unterschiedlichen Bindungstendenz zu den Serumproteinen erfolgt bei der Verdrängung des Farbstoffes durch Elektrolyte eine Verschiebung der Relativprozente der Proteinfraktionen, obwohl die Serumproteine nicht quantitativ verändert werden. Quantitative Untersuchungen unter Zusatz einiger Sulfate zur Entfärbelösung ergeben, verglichen mit dem Ausgangswert, deutliche Verschiebungen des Farbgehaltes der Proteinbanden. Da die prozentual stärkste Entfärbung bei den Globulinen erfolgt, resultiert eine scheinbare Zunahme der Albuminfraktion.

Im Blut wird Kobalt vorwiegend an Albumin, aber auch an $\alpha_{2}$, $\beta$ - und $\gamma$-Globuline (5), Zink an alle Serum- proteine gebunden $(6,7)$. Eine praktisch quantitative Bindung einer Komponente an eine Proteinfraktion und dadurch ausschließliche Entfärbung nur einer $\mathrm{Ei}$ weißbande, haben wir nicht beobachtet, wohl aber teilweise eine stärkere Entfärbung der Proteinfraktionen, die für den eingesetzten Elektrolyt als Transportvehikel dienen. Quantitative Übereinstimmung unserer Ergebnisse mit Experimenten, bei denen Elektrolytzusatz zum nativen Serum erfolgt, würde überraschen, da in unserem Falle die Proteine durch die Behandlung mit Methylalkohol/Eisessig schon weitgehend denaturiert sind. Durch Denaturierung gleicht sich die Bindungsfähigkeit der Proteinfraktionen weitgehend aus (8). Elektrolytzusatz zum Serum beeinflußt den Anfärbevorgang auf andere Weise und wird im Rahmen einer späteren Arbeit behandelt werden.

Herrn Doz. Dr. E. Scirnel, Institut für anorganische Chemie der Universität Innsbruck (Vorstand Prof. Dr. E. HAyEK) danken wir für die Durchführung der röntgenfluoreszenzanalytischen Messungen.

Frau Prof. Dr. Dr. h. c. E. Cremer, Vorstand des physikalisch chemischen Institutes der Universität Innsbruck, danken wir für die Ermöglichung der Durchführung der radiochemischen Messungen.

\section{Literatur}

1. Grassmann, W. und K. Hannig, Hoppe Seyler's Z. physiol. Chem. 290, 1 (1952). - 2. WAchteR, H., Arztl. Laborat. 13, 211 (1967). - 3. WaChteR, H., Arztl. Laborat. 10, 335 (1964). - 4. Dittmer, A., Plasmaeiweiß und Elektrophorese, S. 107, 3. Aufl., VEB Gustav Fischer Verlag Jena (1961). - 5. Horst, W., Klin.
Wschr., 37, 961 (1959). - 6. Bennhold, H., in P. DesGrez und P. M. De Traverse, Transport Function of Plasma Proteins, Elsevier Publishing Company/Amsterdam-London-New York (1966). - 7. Bennhold, H., Klin. Wschr. 41, 109 (1963). 8. Plückthun, H. und H. Görtig, Klin. Wschr. 29, 414 (1951).
Univ.-Doz. Dr. H. Wachter Institut für Medizinische Chemie der Universität Innsbruck Müllerstraße 44

A-6020 Innsbruck 